\title{
Study on the Extraction of Natural Lutein from Marigold
}

$$
\text { Chuang Yang }{ }^{1,} \text { a Mingzhe } \mathrm{Li}^{2, \mathrm{~b}}
$$

${ }^{1}$ Jilin Agricultural Science and Technology University, Jinlin, Jilin, China, 132101

\author{
aemail, bemail,
}

Keywords: Microwave, Marigold, Lutein, Stability

\begin{abstract}
We use the microwave technology to extract the lutein from the marigold. The effects of microwave time, microwave power and solid - liquid ratio on the yield of lutein were studied by single factor test and orthogonal test. The results determine that the best extraction conditions are as follows: microwave time is $30 \mathrm{~s}$, microwave power is $540 \mathrm{~W}$, solid - liquid ratio is 1:30 and the yield of lutein in marigold is $2.6 \%$.
\end{abstract}

\section{Introduction}

Lutein is a kind of active vitamin A carotenoids, it is generally found in fruits, vegetables, flowers and most algae, is the natural natural pigment. The results showed that the content of lutein in cabbage, pepper, mango and orange were the highest among the plants and plants, and the content of lutein in cabbage, kale, spinach, green leaf and marigold was the highest. Fat content is very high and lutein is the predecessor of lutein.

Lutein is composed of three elements, $\mathrm{C}, \mathrm{H}, \mathrm{O}$ in the end of the chain structure contains a hydroxyl group, it exists in the cell membrane hydrophobic phospholipid molecular layer [1], left in the membrane two side is the hydrophilic hydroxyl, this structure can help the greatest degree of zeaxanthin and lutein and easily oxidized cell membrane lipids combine to increase the strength of the cell membrane. The stability of lutein has also been a research topic, for the preservation and storage of lutein has a significant role in the study, the heat stability of lutein in general and it is very sensitive to light, usually stored in the shade of the leaves flavin, lutein is also an antioxidant [2] can prevent the oxygen free radicals on the human body caused by the destruction of oxygen, can inhibit the natural activity of reactive oxygen species, in the human body mechanism can also be generated in the normal metabolism of yellow leaves The amount of production in certain drugs and environmental toxins increases.

Lutein on the retina can play an important role in the protection of macular, when the lack of lutein can lead to macular degeneration and blurred vision. Continue to severe words will appear myopia, visual deterioration and other symptoms. Lutein is a precursor of vitamin A, can be converted into vitamin A in the human body. The main physiological function of lutein to the eye is as an antioxidant and photoprotective effect. The optic nerve is non-renewable [3] is particularly vulnerable to harmful free radical damage and lutein antioxidant can effectively inhibit harmful free Formation. In the spectrum of blue visible light and ultraviolet light wavelength is very similar, will undoubtedly become the most serious damage to the retina light [4], lutein can effectively absorb blue light, retinal cells have a lutein accumulation in that place can effectively prevent the blue light hazards of retinal cells, so as macular at the number of lutein, it is decided to absorb the number of blue, the absorption of the more the smaller the harm to the retina, that is reduced to a minimum.

Microwave extraction process characteristics, high frequency, volatility, thermal characteristics and non-thermal characteristics, these features make the experiment more efficient, faster to get the material you want to extract molecules, and can also reduce the amount of extraction medium, Time-efficient is shortened, energy conservation and environmental protection, to evenly extract the molecular heat [5], this microwave process is different from the traditional thermal extraction process, the traditional thermal extraction process is through the thermal conductivity, heat radiation, etc. from the inside out to transfer energy, and microwave extraction is no heat transfer, the heating is uniform, and heating quickly, is the internal and external colleagues to heat, which reduces the heat conduction process, directly shorten the heating time of the extract, the heat-sensitive material 
extraction is very favorable.

\section{Test Methods and Processes}

Process Flow. Marigold flowers $\rightarrow$ washed by oven drying $\rightarrow$ grinding $\rightarrow$ weighing sample $\rightarrow$ adding ethanol $\rightarrow$ adding sodium hydroxide solution $\rightarrow$ alkaline solution to the environment $\rightarrow$ into the microwave $\rightarrow$ remove the cooling $\rightarrow$ filter $\rightarrow$ leaf yellow sample solution

Standard Curve Drawing. Accurately weighed $0.50 \mathrm{mg}$ lutein standard solution, dissolved with $5.00 \mathrm{~mL}$ absolute ethanol, the concentration of $100.00 \mathrm{mg} / \mathrm{L}$ concentration of working fluid. The prepared lutein solution was prepared into 0.5, 1.0, 1.5, 2.0, $2.5 \mathrm{mg} / \mathrm{L}$ standard solution. The A value was measured at $474 \mathrm{~nm}$, and the regression equation was obtained by plotting the absorbance (X) as the ordinate and the concentration of lutein solution (mff / L) (Y) as the abscissa. Lutein standard curve was:

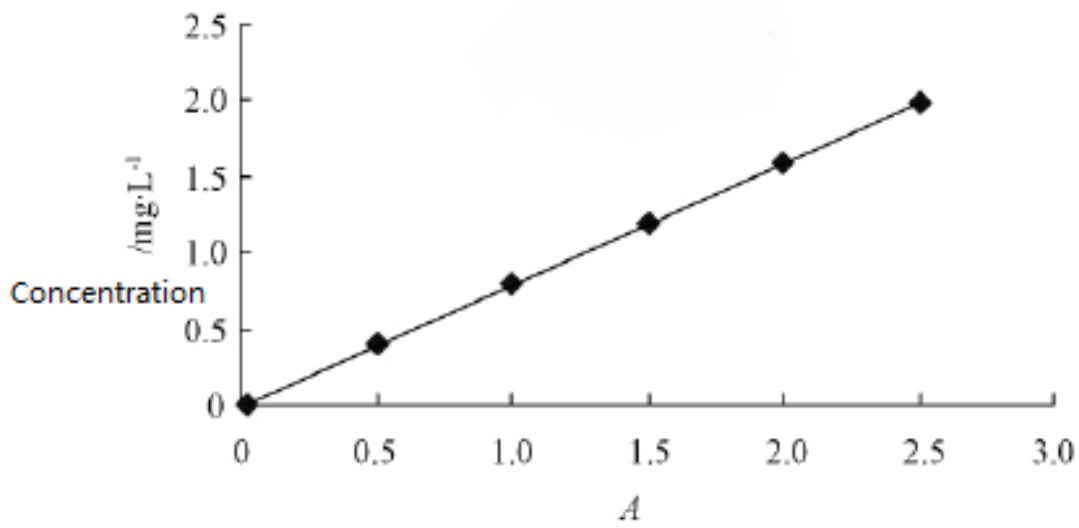

Fig.1 Standard curve of lutein

Regression equation:

$$
\mathrm{Y}=0.8074 \mathrm{X}-0.034, \mathrm{R} 2=0.9996
$$

The Experimental Process and Determination of the Lutein Yield. Take fresh marigold washed 60 0C constant temperature drying oven, crushed into the electronic precision balance weighed about $0.50 \mathrm{~g}$ sample, into the $100 \mathrm{ml}$ Erlenmeyer flask, add anhydrous ethanol solution and $20 \mathrm{ml}$ of distilled water, After fully shaking, add a small amount of sodium hydroxide solution, the solution adjusted to alkaline environment, into the microwave, the microwave after the removal of conical flask, cooled to room temperature, into the centrifuge, after centrifugation filter impurities After the lutein sample solution was taken, the volume of each filtered solution was recorded and diluted 10-fold, and the spectrophotometric value A was obtained at $474 \mathrm{~nm}$ using a spectrophotometer. The factors influencing the yield of lutein were determined by microwave time, microwave power, material ratio and so on, and analyzed by single factor.

\section{Results and Analysis}

The Orthogonal Test Factors and Level Design. On the basis of single factor experiment, orthogonal experiment was carried out by using microwave power, material ratio and microwave time as factors to get the optimum conditions of lutein yield. 
Table. 1 Orthogonal test factor level table

\begin{tabular}{ccccc}
\hline Level & \multicolumn{4}{c}{ Factor } \\
& $\begin{array}{c}\text { A Material ratio } \\
(\mathrm{g} / \mathrm{ml})\end{array}$ & $\begin{array}{c}\text { B Microwave time } \\
(\mathrm{s})\end{array}$ & $\begin{array}{c}\text { C Microwave } \\
\text { power }(\mathrm{w})\end{array}$ \\
\hline 1 & 1 & $: 20$ & 30 & 360 \\
2 & 1 & $: 30$ & 40 & 450 \\
3 & 1 & $: 40$ & 50 & 540 \\
\hline
\end{tabular}

\section{Orthogonal test results}

Table.2 Orthogonal test

Microwave Extraction Orthogonal Experimental Data Sheet

\begin{tabular}{|c|c|c|c|c|c|}
\hline \multirow{5}{*}{$\begin{array}{l}\text { Experiment } \\
\text { number }\end{array}$} & \multicolumn{3}{|c|}{ Factor } & \multirow[t]{5}{*}{ Blank } & \multirow{5}{*}{$\begin{array}{l}\text { Extraction } \\
\text { rate }(\%)\end{array}$} \\
\hline & \multirow{4}{*}{$\begin{array}{c}\text { A Liquid } \\
\text { ratio }(\mathrm{g} / \mathrm{ml})\end{array}$} & \multirow{2}{*}{$\begin{array}{c}\text { B } \\
\text { Microwave }\end{array}$} & \multirow{4}{*}{$\begin{array}{c}\text { C } \\
\text { Microwave } \\
\text { power } \\
\text { (w) }\end{array}$} & & \\
\hline & & & & & \\
\hline & & time $\quad(\mathrm{s})$ & & & \\
\hline & & & & & \\
\hline 1 & 1 & 1 & 1 & 1 & 0.61 \\
\hline 2 & 1 & 2 & 2 & 2 & 0.90 \\
\hline 3 & 1 & 3 & 3 & 3 & 1.50 \\
\hline 4 & 2 & 1 & 2 & 3 & 1.02 \\
\hline 5 & 2 & 2 & 3 & 1 & 2.60 \\
\hline 6 & 2 & 3 & 1 & 2 & 1.80 \\
\hline 7 & 3 & 1 & 3 & 2 & 2.31 \\
\hline 8 & 3 & 2 & 1 & 3 & 1.25 \\
\hline 9 & 3 & 3 & 2 & 1 & 1.84 \\
\hline K1 & 3.01 & 3.94 & 3.66 & 5.05 & \\
\hline K2 & 5.42 & 4.75 & 3.76 & 5.01 & \\
\hline K3 & 5.4 & 5.14 & 6.41 & 3.77 & \\
\hline k1 & 1 & 1.3 & 1.22 & 1.68 & \\
\hline k2 & 1.8 & 1.58 & 1.25 & 1.67 & \\
\hline k3 & 1.8 & 1.71 & 2.14 & 1.26 & \\
\hline $\mathrm{R}$ & 0.8 & 0.41 & 0.92 & 0.42 & \\
\hline
\end{tabular}

The orthogonal experiment data of microwave extraction showed that the best extraction 
condition was A2 because the influence of $C(R)$ factors on the yield of lutein in marigold was microwave power> solid-liquid ratio> extraction time. B2, C3, microwave power $540 \mathrm{w}$, the ratio of material to liquid 1: 30, extraction time 40s, the optimum extraction rate of lutein in marigold is $2.6 \%$

\section{Acknowledgements}

Fund Project: Jilin Agricultural Science and Technology University Youth Fund Project (No.218 [2015] of the Ministry of Agriculture);

\section{References}

[1] Navarrete-Bolanos J L, et al. Improving xanthophylls ex-traction from marigold flower using cellulolytic enzymes [J]. Agric Food Chem, 2004, 52: 3394-3398.

[2] Xu Xiulan; Zhao Guohua; Kan Jianquan; Chen Zongdao Research progress of lutein in grain and oil, 2004, No. 10

[3] Li Haoming. Margarine lutein and its physiological function of the survey[J]. China Food Additives, 2001 (4): 31-33.

[4] Liao Pingtai, Huibo Di, Pei Lingpeng, et al. Antioxidant function of lutein in vitro [J]. FOOD AND FERMENTATION INDUSTRIES, 2005, 31 (4): 46-49.

[5] Nie Yongliang, Wang Wanxu, Du Zhiping, et al. Supercritical CO2 fluid extraction and saponification of lutein extract [J]. Journal of Daily Chemical Science, 2008, 31 (1): 15-18. 